\title{
Measurement Framework for Smart Technology Capability of Construction Industry
}

\author{
Chui Young Yoon
}

\begin{abstract}
In 4th industrial revolution, construction industry has tried to apply smart technology to construction fields in order to efficiently manage and improve construction tasks and activities in a smart technology industry environment. The utilization of smart technology for construction fields is very important for efficient advancement and competitiveness of construction industry. In this industry environment, construction industry has to build its smart technology environment appropriate for construction fields. The smart technology capability of construction industry is a critical expedient for the efficiency of its activities and the improvement of its performances. It has to be systematically controlled and improved to develop the business environment of construction industry and reinforce its competitiveness. Hence, this study develops a measurement framework that can rationally gauge a smart technology capability for construction industry in terms of a construction stage. It can be enable to systematically manage and upgrade the smart technology capability that can efficiently support construction fields. The developed measurement framework is confirmed by reliability analysis and factor analysis based on previous studies. The 12-item measurement scale presented in this study can comprehensively gauge a smart technology capability for a construction industry in a smart technology perspective.
\end{abstract}

Keywords - construction industry, smart technology, smart technology capability, measurement framework

\section{INTRODUCTION}

In this smart technology circumstances, construction industry has utilized smart technology as a critical expedient to retain and advance the construction industry's effectiveness and efficiency in the ever-changing industrial environment [1]. Smart construction industry is to raise the added value to technology-intensive industry from labor-intensive industry through selectively applying cutting-edge IT technology to traditional construction industry [2]. The diverse utilization of smart technology for construction fields will bring the growth of productivity, reinforcement of stability, and cost reduction in future construction industry [3]. Most country is deploying the policy supports and technology development competition of its national level for the growth of productivity, job creation, and the initiative of future market in construction industry fields [3].

Chui Young Yoon/On Kwang Technology Research Center, On Kwang Co. Ltd., Republic of Korea

This research was supported by Basic Science Research Program through the National Research Foundation of Korea (NRF) funded by the Ministry of Education, Science and Technology (NO: 2017R1D1A1B03036086).
Most construction industries have built the smart technology environment to raise the efficiency and performance of their construction fields, and to reinforce their competitiveness in a global construction environment. It is essential to diversely utilize smart technology for all kinds of construction activities. Establishment and management of smart technology environment for construction fields are very crucial to fulfill the efficient construction capability appropriate for construction competitiveness in a global construction environment. Namely, we have to control the smart technology capability of construction industry with an objective and practical measurement framework in order to efficiently build and improve a smart technology environment appropriate for the construction activities and performances. The measurement framework should manage the smart technology capability of construction industry based on the measurement results of smart technology ability for construction fields. However, previous studies have not studied a measurement framework to gauge a smart technology capability of construction industry. Hence, we need an objective measurement framework that can efficiently gauge a smart technology capability for construction industry in terms of its construction stage.

Therefore, this study presents a structural measurement framework that can practically gauge a smart technology capability of construction industry (STCCI) to efficiently execute construction activities, and to systematically build and advance its smart technology environment in terms of a construction stage.

\section{PREVIOUs ReSEARCH}

Smart construction is to accomplish the optimization for efficiency and automation of construction process, virtual construction, intelligence building equipment, and construction logistics through highly advancing construction process and infrastructure [2]. The core technology of smart construction includes the following technologies, such as building information modeling (BIM), mobile, drone, modular, virtual and augmented reality, 3D printer, big data and artificial intelligence (AI), and internet of things (IoT) [3]. The construction stage consists of construction design, construction execution, and operation and maintenance [3]. The core domain of construction design contains the collection and mensuration of construction information, automation of BIM design and virtual construction execution [3]. The critical domain of construction execution comprises automation and unmanned 
control of construction equipment, modular construction execution, and safety and construction management of construction fields [3]. The crucial domain of construction operation and maintenance covers information collection and inspection of construction facilities, and integration platform based on BIM [3].

Smart construction composes sensing, planning and connectivity, and control in terms of a smart construction systems [4]. Smart construction can be described as a hyper-connected and intelligence construction in terms of a hyper-connected and intelligence [5]. Smart construction service can be realized by utilization based on smart network of big data extracting from multitudinous things and devices through hyper-connected and intelligence [5]. Smart construction is a technology to efficiently manage a plan, building, execution, maintenance, control, inspection, and feed-back for construction fields [6]. Smart construction has to consider for enabling a connected system across all stages of plan, design, procurement, execution, and operation and maintenance for construction fields [7]. Smart construction was defined as including characteristics of five elements like sensing and analyzing, environment friendly, green construction, interface-oriented, human centered, and asset management between construction activities for plan, design, procurement, execution, and operation and maintenance as a structure assimilated with IT and construction technology [8]. Smart construction is explained as a construction method that takes an objective for efficiency of construction management and cost cutting of construction with utilizing smart technology of sensing, planning and connectivity, and control through all kinds of construction fields as plan, design, procurement, execution, and operation and maintenance [9]. But, as shown in these previous studies, the smart construction capability has not been researched in previous literature related to smart construction [1]-[9]. Otherwise, we want to utilize the research results related to information technology capability in previous literature.

In previous studies, many studies defined the concepts of information technology capability from the viewpoints of the study researchers [10]-[22]. Several research agencies present their research reports in a specific information technology and solution departments [10]-[22]. Information technology capability is considered the culmination of the sets of hardware, software, services, management practices, and technologies and management skills related to smart technology departments [10][11]. We can explain an information technology capability as the ability to integrate other resources of an organization through the disposition and utilization of one's own information technology resources. Information technology capability is formed by information technology system convention, technology infrastructure, and information technology human resources and information technology relationship assets based on these resource-based perspectives [12]. This research can explain that a kind of information technology ability is to support for organizational activities and workflows by the disposition of information technology resources and integration of other relevant resources. Information technology capability is conceptualized as the extent to which an organization is knowledgeable about and effectively utilizes information technology to manage information technology data within the organization [13][14][15]. The components of information technology capability represent three co-specialized resources: information technology objects; information technology knowledge; and information technology operations [16]. Information technology objects represent computer-based hardware, software, and support personnel [16]. Information technology knowledge is summarized as the extent to which an organization possesses a body of technical knowledge about objects such as computer based systems [16]. Information technology operations are identified as the extent that an organization utilizes smart technology to manage market and customer information [16]. From an information technology system perspective, the measurement of the information technology system level indicates the total capability that includes information technology vision, information technology infrastructure, information technology support, and information technology application and usage [17]. The information technology vision represents an information technology strategy plan and information technology project plan of an organization [17]. The information technology infrastructure includes hardware, networks, system software, and supporting tools [17]. Information technology support refers to information technology organization, information technology direction and institution, and supporting methods for information technology facilities [17]. Information technology application and usage explain the application and utilization that exploit solutions and information technology for an organization's activities [17]. In this research, we can convert an information technology capability to a smart technology capability in a smart technology perspective through utilizing the research results of previous studies.

Hence, based on previous literature and our research results, this study defines a smart technology capability of construction industry (STCCI) as the smart technology capability that a construction industry has to hold for efficiently supporting construction business and performance in terms of a smart technology of construction stage. This research develops the first measurement items for STCCI based on the definition of STCCI and previous studies related to the smart technology ability for construction fields. Next section explains research method, verification of reliability and validity of the developed measurement framework, structure of measurement framework, and conclusion.

\section{RESEARCH METHOD}

\section{A. Outline of Research}

This research firstly developed 21 measurement items for STCCI based on the definitions and components of smart technology for construction fields in previous studies [1]-[22]. The developed measurement items were reviewed and refined 
by the researchers and experts related to smart technology: postdoctoral researchers, professors, and smart technology developers. The construct validity of the developed measurement items is verified to assure that they reasonably gauge STCCI. Our research proved them by showing that the measurement framework was a suitable operational definition of the construct it purported to measure. Previous studies presented diverse methods to verify the validation of a model construct [23]-[26]. Most study used two methods of model construct validation: correlations between total scores and item scores; and factor analysis [23]-[26]. The former ensures that the total score is valid, and the extent to which the item correlates positively with the total score is indicative of the construct's validity for the items [23]-[24]. The score of each item score was subtracted from the total score to exclude spurious part-whole correlation [23]-[24]: the result was a corrected item-total correlation that was then correlated with the item score. The latter, factor analysis, investigates the underlying structure or components of the framework [25][26]. It helped identify factorally pure items that would facilitate more specific hypothesis tests, and to identify the components that make up the total measure [25][26]. The factor-analyzed items were selected, since they had close correlation between each other.

This research also analyzed a measurement scale of criterion-related validity to distinguish the measurement items that may not be closely concerned with STCCI. The generalized measurement item to efficiently gauge STCCI was used as a criterion measurement scale. The measurement provided a measurement scale of criterion-related validity to the extent that each measurement item was correlated with this. The measurement items should represent a favorable or unfavorable attitude toward the object in question [25][26]. When the measurement item is ambiguous or appears to present a neutral attitude, it should be deleted [25][26]. We examined a measurement framework of criterion-related validity to identify measurement items that did not show favorable or unfavorable attitudes. We took out all of the measurement items in a measurement framework from the domain of a single construct, and responses to these measurement items should be highly inter-correlated. The corrected item-total correlation accounts for a measurement framework of this.

In this questionnaire survey, the measurement questionnaire used a five-point Likert-type scale as provided in previous studies; denoting, 1: not at all; 2: a little; 3: moderate; 4: good; and 5: very good. This research carried out our measurement questionnaire for construction fields like architecture, civil engineering, industrial environment, and landscaping. This questionnaire also consists of three main departments. The first department indicates the backgrounds and objectives, main contents, and response methods of this questionnaire. The second department asks for respondents to provide general information, such as construction fields, firm's size and revenue, and business history of their companies. The last department provides the measurement items for the respondents working in construction fields. This research obtained the questionnaire data from various construction fields so that the measurement results can be generalized. Our research executed two kinds of survey methods: direct collection and e-mail. The respondents either directly mailed back the completed questionnaires or research assistants collected them two-four weeks later. The collected questionnaires represented 29.5 percent of all the target respondents.

\section{B. Sample Characteristics}

In this questionnaire survey, this research collected 116 responses form 400 respondents in four construction fields. The respondents indicated various construction fields, firm size and revenue, and business history. We removed three incomplete or ambiguous questionnaires, remaining 113 usable questionnaires for statistical analysis. The respondents of this questionnaire in terms of construction fields were classified as architecture (34.5\%), civil engineering (25.7\%), industrial environment (21.9\%), and landscaping (15.9\%). The respondents classified themselves as top manager (7.1\%), middle manager $(42.5 \%)$, and worker $(50.4 \%)$. The respondents in four construction fields had on average 7.3 years' experience (S.D. $=1.13$ ) in their construction fields, their average age was 36.4 years old (S.D.=5.12), and their gender, male (74.3\%) and female $(25.7 \%)$. Our research used various samples that can completely understand their STCCI with practical affairs working at their construction fields for more than about 3 years in order to raise the generalization of this research results. Hence, the respondents could rationally present the right responses for our questionnaire survey.

\section{C.Analysis and Discussion}

Our research generated the analysis results from the obtained measurement questionnaires. The measurement items were deleted when their correlation with the corrected item-total correlation was $<0.5$ or when their correlation with the criterion scales was $<0.6$ [23][24]. The correlations with the corrected item-total correlation and the criterion item were significant at $\mathrm{p}$ $\leq 0.01$ and similar to those used by others in previous studies [23][24]. This research utilized factor analysis to confirm the validity of the developed measurement framework and measurement items [25][26]. We also put to use this analysis to distinguish the underlying factors or components that consist of the STCCI construct.

This research deleted inadequate items for the measurement framework based on the analysis results of the obtained measurement questionnaire. We sufficiently considered high criteria to extract the objective measurement items for STCCI. That is, the first 21 measurement items remained a 13-item scale prior to conducting factor analysis. The sample of 113 responses was explored by utilizing principal components analysis as the extraction technique with the varimax method of rotation. The measurement items with many multiple loadings may be good measurement items for STCCI, but this blurs the distinction between factors by including these items in the scale [25][26]. The measurement items, having factor loadings greater than 0.3 on other factors, were removed from the measurement framework to improve the distinction between factors [25][26]. In general, our research deleted one measurement item, since they got the lowest correlations with a criterion and the lowest factor loadings. This deletion resulted in a 12-item scale to measure STCCI. In the analysis results, one 
factor with Eigen value $=8.1$ explained as explaining $67 \%$ of the variance. Each of the 12 measurement items had a factor loading $>0.60$. Table 1 shows the analysis results of the 12 measurement items. As presented in Table I, each of the 12-measurement items had a corrected item-total correlation of $>0.60$ and a correlation with the criterion measure of $>0.60$. The correlation for each of the 12-measurement items was positive and significant $(\mathrm{p} \leq 0.01)$. This 12 -item scale had reliability (Cronbach's alpha) of $>0.790$ and a corrected item-total correlation of $>0.690$. The 12-measurement items represent a reliable and valid measurement framework to gauge STCCI.

TABLE I

FACTOR LOADING, RELIABILITY, AND VALIDITY OF STCCI CONSTRUCT

\begin{tabular}{|c|c|c|c|c|c|}
\hline \multirow{2}{*}{ Variable } & \multicolumn{3}{|c|}{ Factor Loading } & \multirow{2}{*}{$\begin{array}{c}\text { Corrected } \\
\text { Item-Total } \\
\text { Correlation }\end{array}$} & \multirow{2}{*}{$\begin{array}{c}\text { Coefficients } \\
\text { Alpha }\end{array}$} \\
\hline & Factor 1 & Factor 2 & Factor 3 & & \\
\hline V02 & 0.786 & & & 0.682 & \multirow{4}{*}{0.803} \\
\hline V04 & 0.775 & & & 0.747 & \\
\hline V05 & 0.747 & & & 0.689 & \\
\hline V07 & 0.672 & & & 0.724 & \\
\hline V08 & & 0.789 & & 0.782 & \multirow{4}{*}{0.798} \\
\hline V10 & & 0.761 & & 0.735 & \\
\hline V11 & & 0.723 & & 0.768 & \\
\hline V13 & & 0.654 & & 0.694 & \\
\hline V15 & & & 0.781 & 0.768 & \multirow{4}{*}{0.796} \\
\hline V18 & & & 0.769 & 0.781 & \\
\hline V20 & & & 0.712 & 0.804 & \\
\hline V21 & & & 0.613 & 0.719 & \\
\hline
\end{tabular}

* Significant at $\mathrm{p} \leq 0.01$

In addition, we should endeavor to provide additional facts of the measurement framework's validity and reliability to verify more objective measurement items. Many research findings and case studies will be able to gather the supplementary proofs of its validity and reliability. We can find more scientific and practical scale for the proper application of construction fields through reflecting the measurement results of many findings and case studies.

\section{StRUCTURE OF MEASUREMENT FrAMEWORK}

This research developed the 12 measurement items that can reasonably gauge STCCI through examining the analysis results for our measurement questionnaire. We classified three factor groups based on the analysis results of factor analysis for the measurement items. These factor groups means the potential factors as major components to efficiently measure STCCI. From exploring the measurement items of each factor group, our research identified the following three main factors: factor 1 : smart construction design technology; factor 2: smart construction execution technology, and factor 3: smart construction operation and maintenance technology. These factors include the overall measurement components for STCCI from smart construction design technology to smart construction operation and maintenance technology in construction stage. Smart construction design technology presents the smart technology related to the architecture design in construction stage. It includes the smart technology for the collection and analysis of construction information, architecture mensuration, automation of design for building information modeling, and virtual building execution. Smart construction execution technology indicates the smart technology related to architecture execution in construction stage. It contains automation of construction equipment, unmanned control, module execution, safety management, and construction management for construction work fields. Smart construction operation and maintenance technology refers to the smart technology related to operation and maintenance of architecture facilities in construction stage. It comprises the smart technology related to information collection and inspection for architecture facilities, management for architecture facilities, and integration platform based on building information modeling.

In general, these findings describe a structural framework that can measure STCCI in terms of construction stage from smart construction design technology to smart construction operation and maintenance technology, including 3 measurement factors and 12 measurement items.

The developed measurement framework includes three measurement factors such as smart construction design technology, smart construction execution technology, and smart construction operation and maintenance technology (Fig.1). Each factor consists of four measurement items. As shown in Table I and Fig.1, smart construction design technology contains the measurement items, such as V02, V04, V05, and V07. Smart construction execution technology includes the measurement items: V08, V09, V11, and V13. Smart construction operation and maintenance technology has the measurement items: V15, V18, V20, and V21. These measurement factors influences STCCI that presents the smart technology capability of construction industry in construction stage. It is very important to control and upgrade STCCI through measuring of STCCI by using a valid and reliable measurement framework. Our findings can facilitate efficient improvement of a STCCI by utilizing the measurement results for construction fields by this measurement framework. Measurement of STCCI is a critical method to examine the real situation for smart technology capability of a construction industry based on the smart technology for construction design, construction execution, and construction operation and maintenance. Namely, grasping the STCCI structure is essential to understand the success of STCCI that denotes the smart technology capability in order to efficiently support its construction fields. This research can use the structural framework to measure STCCI, and perhaps even as a reasonable measure. 


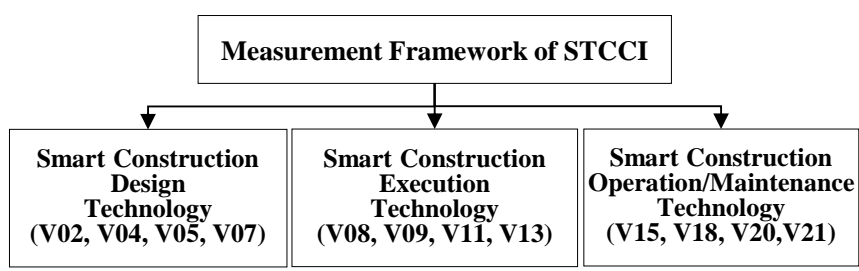

Smart Construction Design Technology (SCDT)

-V02: Collection and analysis of construction information?

-V04: Architecture mensuration in construction fields?

-V05: Automation of design for building information modeling?

-V07: Virtual building execution in construction fields?

Smart Construction Execution Technology (SCET)

-V08: Automation of construction equipment in construction fields?

-V09: Unmanned control and module execution in construction fields?

-V11: Management for construction work in construction fields?

-V13: Safety management in construction fields?

Smart Construction Operation and Maintenance Technology (SCOMT)

-V15: Information collection and analysis of architecture facilities?

-V18: Inspection of architecture facilities in construction fields?

-V20: Building information modeling in construction fields?

-V21: Management of architecture facilities in construction fields?

Fig. 1 Structure of the developed measurement framework for STCCI

Our search also analyzed the correlation between the measurement factors, and the correlation between each factor and STCCI. Because there are the factors affecting STCCI, the analysis of their correlation is very important for the effective improvement of STCCI and for the efficient utilization of the developed measurement framework in construction fields.

TABLE II

CORRELATION MATRIX

\begin{tabular}{|l|c|c|c|c|}
\hline CORRELATION MATRIX \\
\hline Division & & $(2)$ & $(3)$ & $(4)$ \\
\hline STCCI & $(1)$ & 0.42 & 0.47 & 0.39 \\
\hline Smart Construction Design Technology & $(2)$ & & 0.41 & 0.37 \\
\hline $\begin{array}{l}\text { Smart Construction Execution } \\
\text { Technology }\end{array}$ & $(3)$ & & & 0.36 \\
\hline $\begin{array}{l}\text { Smart Construction Operation and } \\
\text { Maintenance Technology }\end{array}$ & $(4)$ & & & \\
\hline
\end{tabular}

Their mutual correlation is complex and may be influenced by other variables. This research examined how they were correlated in order to indagate the correlation between smart construction design technology, smart construction execution technology, and smart operation and maintenance technology, and STCCI, as presented in Table II. In correlation analysis, the smart construction execution technology was the most influence factor for STCCI. From our analysis results, we firstly consider the smart construction execution technology to efficiently advance the STCCI.

\section{CONCLUSION}

Nowadays, smart technology is utilizing for all kinds of industry fields in a smart industry environment. The utilization capability of smart technology is a key means for industrial activities and competitiveness of an industry in a global industry environment. In this smart industry environment, we need a control framework for managing and advancing the smart technology capability of an industry. This research provides a comprehensive and objective measurement framework that can gauge perceived STCCI in a global industry environment. The STCCI indicates the smart technology capability to support construction fields in construction stage. The developed measurement framework can be utilized for a research and practical purpose on the smart technology capability of construction fields. The developed measurement framework with adequate validity and reliability presents a comprehensive and objective method to grasp the real situations for STCCI in construction fields.

Therefore, this study presents a structural measurement framework that can reasonably gauge the STCCI to efficiently perform construction business, and advance their performance and competitiveness in a global industry environment. This research can also support for effectively establishing a smart technology environment appropriate for construction fields. Our findings provide a new direction and groundwork for the practical and scientific research related to the smart technology ability of construction fields. In future research, we will provide the practicality of the developed measurement framework for STCCI through providing the measurement results by applying it to many construction fields.

\section{REFERENCES}

[1] G D. M. Kim, "Smart Construction AND Its Component Technology," Journal of Drive and Control, vol. 14, no. 3, pp. 59-64, September 2017.

[2] H. S. Chun, "A Study on Convergence Service between Construction and Information Technology," ETRI Technology Economics Series, pp. 422-425, 2010.

[3] J. M. Kang, H. A. Ko, I. J. Hwang, and S. Yoon, "Policy and Technology Development Strategy for Smart Construction," Proceeding of Conference for Korean Society of Civil Engineers, pp. 122-123, October 2018.

[4] Y. C. BaiK and H. S. Kim, "Construction IT Convergence Technology," The Journal of The Korean Institute of Communication Sciences, vol. 30, no. 10, pp. 25-31, September 2013.

[5] C. H. Choi, "A Brief Review for Smart Construction based on Hyper-Connected and Intelligence," Journal of The Korean Society of Civil Engineers, vol. 66, no. 9, pp. 12-13, September 2018.

[6] T. W. Kang, N. C. Baik, S. S. Ahn, and J. A. Ha, "Smart City Technology Classification System for Smart City Construction," Proceeding of Conference for Korean Society of Civil Engineers, pp. 150-151, October 2016.

[7] J. Y. Kim, I. G. Chung, and S. O. Byun, "Application of Smart Construction Technology for Innovation of Construction Works," Journal of the Korean Society of Civil Engineers," vol. 65, no. 6, pp. 20-23, June 2017.

[8] The Ministry of Knowledge Economy, "IT R\&D Development Strategy," Korea Evaluation Institute of Industry Technology, pp. 905-1040, September 2010.

[9] The Boston Consulting Group, Project Report of Infrastructure Competitiveness Diagnosis and Future Development Strategy for Construction Industry in The 4th Industrial Revolution, The Boston Consulting Group Report, pp. 1-2, 2017.

[10] H. Jiao, C. Chang, and Y. Lu, "The Realtionship on Information Technology Capability and Performance: An Empirical Research in the Context of China's Yangtze River Delta Region," Proceeding of The 
IEEE International Conference on Industrial Engineering and Engineering Management, pp. 872-876, 2008. https://doi.org/10.1109/IEEM.2008.4737994

[11] A. S. Bharadwaj, S. G. Bharadwaj, and R. K. Been, "Information Technology Effects on Firm Performance as Measured by Tobin's q, Management Science," vol. 45, no. 7, pp. 1008-1024, 1999. https://doi.org/10.1287/mnsc.45.7.1008

[12] A. S. Bharadwaj, "A resource-based perspective on information technology capability and firm performance: an empirical investigation," MIS Quarterly, vol. 24, no. 1, pp. 169-196, 2000 https://doi.org/10.2307/3250983

[13] W. R. King, "IT capability, business process, and impact on the bottom line," Journal of Information System Management, vo. 19, no. 2, pp. $85-87,2002$. https://doi.org/10.1201/1078/43200.19.2.20020228/35142.8

[14] Z. Qingfeng and Z. Daqing, "The Impact of IT Capability on Enterprise Performance: An Empirical Study in China," WiCOM, pp. 1-6, 2008.

[15] Q. Cheng, R. Zhang, and Y. Tian, "Study on Information Technology Capabilities based on Value Net Theory," Proceeding of The international Symposium on Electronic Commerce and Security, pp. 1045-1050, 2008. https://doi.org/10.1109/ISECS.2008.203

[16] J. Peppard and J. Ward, "Beyond strategic information systems: towards an IS capability, Journal of Strategic Information Systems, vol. 13, pp. 167-194, 2004. https://doi.org/10.1016/j.jsis.2004.02.002

[17] C. S. Leem and S. K. Kim, "Introduction to an integrated methodology for development and implementation of enterprise information systems," The Journal of Systems and Software, vol. 60, pp. 249-261, 2002. https://doi.org/10.1016/S0164-1212(01)00096-6

[18] L. Wang and P. Alam, "Information Technology Capability: Firm Valuation, Earnings Uncertainty, and Forecast Accuracy," Journal of Information Systems, vol. 21, no. 2, pp. 7-49, 2007. https://doi.org/10.2308/jis.2007.21.2.27

[19] T. C. Powell and A. Dent-Micallef, "Information technology as competitive advantage: the role of human, business, and technology resources," Strategy Management Journal, vol. 18, no. 5, pp. 375-405, 1997. https://doi.org/10.1002/(SICI)1097-0266(199705)18:5<375::AID-SMJ8 76>3.3.CO;2-Z

[20] W. Kettinger, V. Gover, and S. Guha, "Strategy information systems revisited: A Study in Sustainability and Performance," IS Quarterly, vol. 18 , no. 1 , pp. $31-58,1994$ https://doi.org/10.2307/249609

[21] D. M. Lee, E. M. Trauth, and D. Farwell, "Critical skills and knowledge requirement of IS professionals: a joint academic and industry investigation," MIS Quarterly, vol. 19, no. 3, pp. 313-340, 1995. https://doi.org/10.2307/249598

[22] C. C. Pegels and M. V. Thirumurthy, "The Impact of Technology Strategy on Firm Performance," IEEE Transaction on Engineering Management, vol. 43, no. 3, pp. 246-249, 1996. https://doi.org/10.1109/17.511835

[23] J. Etezadi-Amoli and A. F. Farhoomand, "A Structural Model of End User Information Satisfaction and User Performance," Information \& Management, vol. 30, pp. 65-73, 1996. https://doi.org/10.1016/0378-7206(95)00052-6

[24] R. McHancy, R. Hightower, and J. Pearson, "A validation of end-user computing satisfaction instrument in Taiwan," Information \&Management, vol. 39, pp. 503-511, 2002. https://doi.org/10.1016/S0378-7206(01)00119-7

[25] G. Torkzadeh and W. J. Doll, "The Development of a Tool for Measuring the Perceived Impact of Information Technology on Work," Omega, International Journal of Measurement Science, vol. 27, pp. 327-339, 1999. https://doi.org/10.1016/S0305-0483(98)00049-8

[26] G. Torkzadeh and J. W. Lee, "Measures of Perceived End-user's Information Skills," Information \& Management, vol. 40, pp. 607-615, 2003.

https://doi.org/10.1016/S0378-7206(02)00090-3 